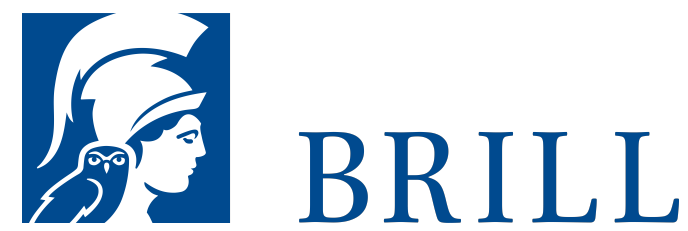

\title{
Auf dem Kampfplatz der Metaphysik
}

Kritische Studien zur transtemporalen Identität von Personen

Author: Anne Sophie Meincke

Die gegenwärtige Diskussion um Personen und ihre transtemporale Identität steckt in einem Dilemma: Reduktionisten demontieren die Idee transtemporaler personaler Identität im Rahmen ihrer empirischen Analyse; Nichtreduktionisten verwandeln sie im Gegenzug in ein substanzmetaphysisches Mysterium. Transtemporale personale Identität wird entweder, wegerklärt' oder, pseudoerklärt'. Die dilemmatische Struktur des Diskurses stellt unsere alltägliche Überzeugung, daß Personen länger als einen Augenblick existieren, radikal in Frage: In dem Maße, wie die transtemporale Identität von Personen sich offenbar systematisch einer befriedigenden metaphysischen Erklärung entzieht, erheben sich fundamentale Zweifel an ihrer Wirklichkeit. Mindestens ebenso fragwürdig wird aber auch die Metaphysik, die sich erfolglos an einer solchen Erklärung versucht. Die vorliegenden kritischen Studien erkunden die Möglichkeiten eines Ausweges aus dem, wie sich zeigt, weder neuen noch harmlosen Dilemma. Mit Kants Augen betrachtet manifestiert sich hier vielmehr eine fundamentale Dialektik, deren Gründe in der Struktur der menschlichen Vernunft liegen und in deren Folge die Metaphysik überhaupt einem unergiebigen Kampfplatz gleicht. Die Möglichkeit einer befriedigenden metaphysischen Erklärung transtemporaler personaler Identität entscheidet sich an der Möglichkeit einer >guten $<$ Metaphysik, die jene...

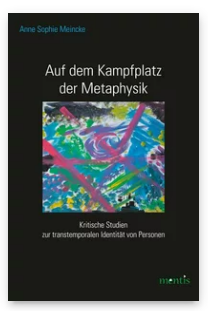

Pages: 356

Seiten

Language:

German

Subjects:

General,

Philosophy

Publisher: Brill | mentis

E-Book (PDF)

Released online: 20 Aug 2015

ISBN: 978-3-

95743-922-2

List price

Paperback

Publication date:

o1 Sep 2015

ISBN: 978-3-

95743-005-2

List price 
For more information see brill.com

Order information: Order online at brill.com +44330 333 0049 | customerservices@brill.com Submission information: brill.com/authors

Titles published by Brill | Fink, Brill | mentis or Brill | Schöningh: +49(o)715413279216| brill@brocom.de 